\title{
Patient-centered care interventions for the management of alcohol use disorders: a systematic review of randomized controlled trials
}

\author{
Pablo Barrio \\ Antoni Gual \\ Neurosciences Institute, Hospital \\ Clinic, Institut d'Investigacions \\ Biomèdiques Agustí Pi i Sunyer, \\ Barcelona, Spain
}

This article was published in the following Dove Press journal:

Patient Preference and Adherence

15 September 2016

Number of times this article has been viewed

Issues: Patient-centered care (PCC) is increasingly accepted as an integral component of good health care, including addiction medicine. However, its implementation has been controversial in people with alcohol use disorders.

Approach: A systematic search strategy was devised to find completed randomized controlled trials enrolling adults ( $>18$ years) with alcohol use disorders. Studies had to use a PCC approach such that they should have been individualized, respectful to the patients' own goals, and empowering. Studies until September 2015 were searched using PubMed, Scopus, the Cochrane Library, PsychINFO, and Web of Knowledge.

Key findings: In total, 40 studies enrolling 16,020 patients met the inclusion criteria. Assessment revealed two main categories of study: psychosocial ( $n=35$ based on motivational interviewing) and pharmacological ( $n=5$ based on an as needed dosing regimen). Psychosocial interventions were further classified according to the presence or absence of an active comparator. When no active comparator was present, studies were classified according to the number of sessions $(\geq 1)$. Results from single sessions of motivational interviewing showed no clear benefit on alcohol consumption outcomes, with few studies indicating benefit of PCC versus control. Although the results for studies of multiple sessions of counseling were also mixed, many did show a significant benefit of the PCC intervention. By contrast, studies consistently demonstrated a benefit of pharmacologically supported PCC interventions, with most of the differences reaching statistical significance.

Implications: PCC-based interventions may be beneficial for reducing alcohol consumption in people with alcohol use disorders.

Keywords: psychosocial intervention, pharmacological intervention, motivational interviewing, as-needed

\section{Introduction}

The Institute of Medicine has included patient-centered care (PCC) as one of the major aims in care quality and defines it as "providing care that is respectful of and responsive to individual patient preferences, needs, and values, and ensuring that patient values guide all clinical decisions". ${ }^{1}$ Although not a new phenomenon, it has recently attracted renewed attention. ${ }^{2,3}$ PCC advocates for a shift from disease-oriented to patient-oriented medicine. Doctors should no longer be authoritative figures who make all the relevant decisions. Instead, they must engage in a shared decision-making model where patients are acknowledged to be experts with regard to their own symptoms and values and where they are recognized as unique and diverse. In such a model, the responsibility is shared between a patient and a physician, and the physician's key role is to strengthen the patient's capabilities to handle his or her part of responsibility. ${ }^{4}$
Correspondence: Pablo Barrio Neurosciences Institute, Hospital Clinic IDIBAPS, Carrer de Villlarroel I70, 08036 Barcelona, Spain Tel +34 932275400 ext 3167 Email pbarrio@clinic.ub.es 
Application of PCC in the field of mental disorders remains a controversial issue. It has long been argued that patients with psychiatric disorders are vulnerable to impediments in decision making, ${ }^{5-8}$ and a paternalistic approach has been the preferred norm in the field. ${ }^{9,10}$ Conversely, a number of studies indicate that patients engaged in the decisionmaking process show greater satisfaction and collaboration, with greater efficacy of treatment. ${ }^{11,12}$

While considering the field of alcohol use disorders, it is also likely that ideological bias and stigma have exacerbated the paternalistic approach. The harmful use of alcohol is one of the world's leading health risks and is the leading risk factor for death of people aged 15-49 years. ${ }^{13}$ However, patients with alcohol use disorders often receive a lower quality of health care than those with other chronic conditions; many dependent patients go without treatment, and even when they are treated, pharmacotherapy is underutilized. ${ }^{14-16}$ Abstinence has been the prevailing goal, usually irrespective of patients' own aims or desire. ${ }^{17}$ Crucially, patients do not always view abstinence as an acceptable, desirable, or realistic treatment goal, and there is an increasing debate about the possibility and the convenience of broadening treatment goals in accordance with a PCC model. ${ }^{18}$ For example, this could mean establishing reduction in heavy drinking as a possible objective for some patients. ${ }^{18-20}$ Reduction of alcohol consumption has been shown to reduce the annual and lifetime risk of alcohol-related death, and it could attract patients who are currently not inclined to seek treatment or do not accept abstinence as a treatment goal. ${ }^{20-22}$ Indeed studies show that patients with alcohol use disorders are more likely to achieve self-set goals (eg, reduction or abstinence), rather than goals that are imposed on them. ${ }^{23,24}$

Several treatment options (psychosocial and pharmacological) are available for people with alcohol use disorders, but no single therapy has been proven to be more effective than another. PCC and shared decision making are considered especially appropriate when outcomes of the different treatments are similar and when an active role of the patient is needed. ${ }^{25}$ Thus, some experts consider alcohol use disorders as potentially a suitable situation to use a PCC approach. ${ }^{2}$ Although some of the components of PCC might have been previously tested for the treatment of alcohol use disorders, for example, in the form of individually tailored feedback and treatment, these have not been systematically assessed in a cohesive manner. The aim of this review was to systematically assess the efficacy of interventions based on a PCC health care approach, both pharmacological and psychosocial, for the management of alcohol use disorders.

\section{Methods}

This systematic review was conducted in accordance with the principles recommended by the Cochrane Handbook for Systematic Reviews of Interventions. ${ }^{26}$ The Preferred Reporting Items for Systematic Reviews and Meta-Analysis guidance was followed for the reporting of procedures; its checklist can be seen in Supplementary materials.

\section{Definition of PCC}

Although patient centeredness is not an easy concept to define in a concise manner, a previous systematic review operationalized it under four defining attributes: holistic, individualized, respectful, and empowering. ${ }^{27}$ Many studies might be considered as PCC, but they might not use this exact expression, or any of the attributes of PCC previously reported. Thus, in order to conduct an appropriately sensitive electronic search, we predefined several adjectives and expressions to cover the four attributes. For example, alternative terms for "empowering" included "patient involvement", "patient perspective", "shared decision-making", and "patient decision", and alternative terms for "individualized" included "tailored", "personalized", and "customized".

\section{Data sources and searches}

The following databases were searched: PubMed, Scopus (which contains EMBASE), the Cochrane Library, PsychINFO, and the Web of Knowledge. The search strategies for PubMed, Scopus, and the Cochrane Library are listed in Supplementary materials. The searches were run until September 2015. Additional hand searches of the reference lists of included randomized controlled trial and relevant systematic reviews were conducted. Finally, the following clinical trial registries were also searched for relevant studies: ClinicalTrials.gov, ISRCTN Register, UK Clinical Trials Gateway, and metaRegister of Controlled Trials.

\section{Study selection}

Individual (not cluster) randomized controlled trials enrolling adults ( $\geq 18$ years) with alcohol use disorders (including hazardous or harmful drinking, alcohol dependence, or any other alcohol use disorder) were included. All the studies had to use a PCC approach such that they should have been individualized, respectful to the patients' own goals, and empowering. Computerized interventions were not included in this review.

As described earlier, although interventions might not have been described with these same adjectives, they were fully reviewed to check whether they met the criteria (ie, the description of the intervention was individually assessed 
to determine whether it could be considered PCC). Studies could use any standardized outcome regarding alcohol consumption (eg, heavy drinking days, grams of alcohol, days of abstinence, percentage of patients drinking below recommended limits on validated screening tools). Only publications in English were considered.

To homogenize the review, studies of patient populations with psychiatric comorbidities were excluded from this review as were studies including populations with relevant and differential psychological variables (eg, mandated or incarcerated patients and pregnant women). Studies conducted in the inpatient setting and short-term studies with $<3$ months of follow-up were also excluded. Studies using cover stories where patients did not know the real intention of the intervention were also excluded, as this is clearly contrary to the concept of PCC. Finally, any comparator was eligible as long as it was not PCC based.

\section{Data extraction}

$\mathrm{PB}$ and AG independently screened all the studies for inclusion. Disagreements were resolved by discussion when possible. If not, a third person was consulted. Data were extracted by $\mathrm{PB}$ and independently checked by AG. The extracted data consisted of participant characteristics, setting, study methods, intervention characteristics, comparators, outcomes, and results.

\section{Quality assessment}

PB and AG independently evaluated the quality of the studies. Following the Cochrane guidelines and the methods used in a recent systematic review undertaken by Mdege et al, ${ }^{28}$ a domain-based approach was used. The following criteria were applied: power calculation, adequacy of randomization, allocation concealment, adjustment for covariates in the analysis, blinding of participants when possible, blinding of outcome assessors, explanation of dropouts, and use of intention-to-treat analysis.

\section{Data synthesis}

Considerable heterogeneity existed between the studies, mainly in terms of reported outcomes, how the outcomes were defined and reported, and the duration of the studies. Given the different methodologies that were employed, the studies were grouped according to whether they primarily assessed a pharmacological or a psychosocial intervention. In the psychosocial group, a further grouping was made according to the number of sessions received, categorizing studies between 1 or $>1$ sessions.
A meta-analysis was conducted on the basis of our findings, by trying to build an outcome construct based on construct validity. However, given the significant methodological issues involved, the analysis was deemed inappropriate and a narrative synthesis was instead conducted.

\section{Results}

\section{Literature search}

A total of 7,048 records were screened through the search strategy, and 115 full-text articles were assessed for eligibility. An additional reference was identified by hand searching, and eventually, after exclusion criteria were applied (reasons for exclusion of full-text papers are available in the Supplementary materials), a total of 40 studies were included in the systematic review. ${ }^{29-68}$ Figure $1 \mathrm{~A}$ depicts the flow diagram of the study.

\section{Study characteristics}

The 40 studies included in this review involved a total of 16,020 enrolled patients. Sample size in each study ranged from 54 to 987 patients. An initial assessment of the studies revealed two groups according to the main treatment evaluated: psychosocial or pharmacological, with 35 evaluating psychosocial interventions and five evaluating primarily pharmacological interventions.

All psychosocial interventions that met the inclusion criteria in this review were based on motivational interviewing (MI) principles, which might be considered as the cornerstone of patient-centered psychosocial interventions nowadays. MI is defined as "a directive, client-centered counseling style for eliciting behavior change by helping clients to explore and resolve ambivalence" ${ }^{69}$ Compared to nondirective counseling, it is more focused and goal directed. The examination and resolution of ambivalence is its central purpose, and the counselor is intentionally directive in pursuing this goal.

Regarding pharmacological interventions, all those fulfilling the inclusion criteria were based on the "as needed" concept. The "as needed" [or pro re nata] treatment paradigm is a well-understood medical concept, where the patient takes the medication in response to individual circumstances and not on a scheduled basis. Although it has been a standard practice for many years in asthma, diabetic, and allergy care, it represents a paradigm shift in the way that pharmacotherapy is used in the management of alcohol use disorders. ${ }^{70}$

For further grouping studies, psychosocial interventions based on MI and with no active comparator (defined as receiving no further intervention or receiving only information, either orally or written materials) were divided 


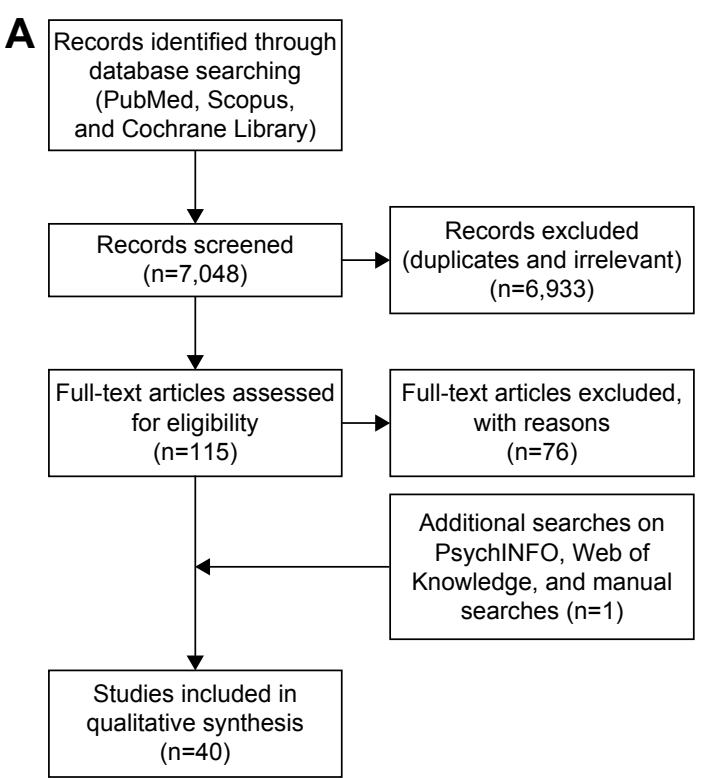

Figure I (A) Study flow chart and (B) quality assessment. Abbreviation: ITT, intention-to-treat.

according to the number of sessions they contained ( 1 or $>1$ ), while the studies containing an active comparator (like cognitive behavioral therapy [CBT], for example) were included in a separate category. Thus, four categories were created to report the results of the systematic review: single-session PCC with no active comparator, more than one session PCC with no active comparator, $\mathrm{PCC}$ with active comparator, and patient-centered pharmacological interventions.

\section{Quality assessment}

The results of quality assessment of the included studies are shown in Supplementary materials. Overall, less than half (42.5\%) of the studies were deemed as adequately powered, $57.5 \%$ had an adequate randomization, and $45 \%$ adequate allocation concealment. Around two-thirds (65\%) used adjusted analysis and $67.5 \%$ reported blinding of the outcome assessors, and all but one study reported adequate information on the patients who dropped-out. Most (65\%) of the studies stated clearly an intention-to-treat analysis (Figure 1B). In psychosocial intervention studies, it was not considered possible to blind participants to the delivered intervention; therefore, participant blinding was only assessed in pharmacological intervention studies, which were all deemed as adequate on this item.

\section{Efficacy of PCC}

\section{Single-session PCC with no active comparator}

Seventeen studies were included in this subgroup (Table 1). ${ }^{29-45}$ Globally, they failed to show a clear benefit of the PCC intervention over the control groups.

\section{B}

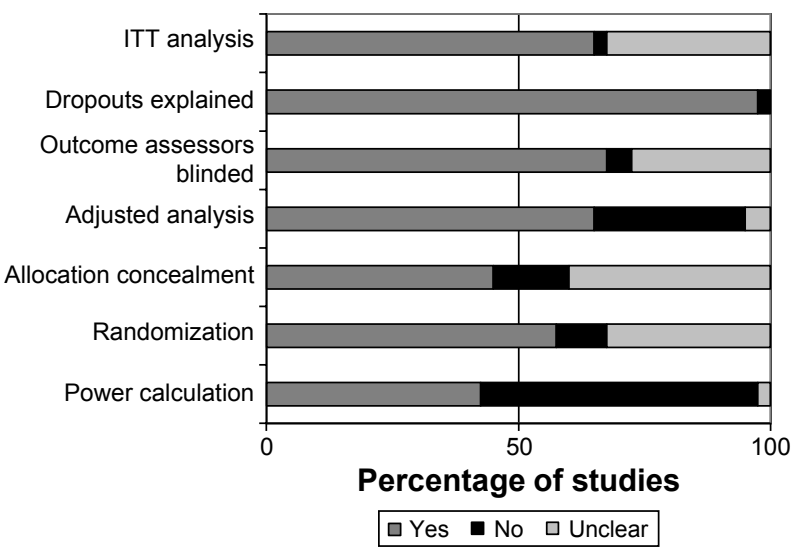

\section{Amount and frequency of alcohol consumption}

Seven studies reported on the number of drinks per week at study end, ${ }^{35-37,40,42-44}$ with only Daeppen et a ${ }^{36}$ reporting a statistically significant difference from baseline to follow-up $(-1.5$ vs $0.8 ; P=0.004)$ favoring the PCC group.

Bischof et al reported a nonsignificant difference in grams of alcohol per day between groups,${ }^{30}$ Emmen et al reported a nonsignificant difference in drinks per day, ${ }^{38}$ and Soderstrom et al reported on the number of drinks in the last 90 days, with no differences between groups. ${ }^{45}$

Five studies reported the number of drinks per drinking day. Four could not find significant differences, ${ }^{33-35,44}$ while Carey et al only reported a small effect size, with no significance value. ${ }^{32}$

Four studies reported on drinking days per week, ${ }^{34,35,42,44}$ none of them reaching statistical significance between groups. Similarly, Lee et al reported on drinking days/month, with no differences between groups ${ }^{41}$ Chang et al reported no differences in the percentage of drinking days between groups, ${ }^{33}$ and Senft et a ${ }^{44}$ reported no differences in the percentages of abstinent patients.

\section{Hazardous and heavy drinking}

Seven studies reported on the number of binge episodes per month..$^{33,35-37,39,41,43}$ Only Daeppen et al (2011) reported a statistically significant difference favoring the PCC group (baseline to follow-up difference -1.5 vs $-0.8, P=0.04$ ). ${ }^{36}$

Murphy et al reported the number of binges per week and Soderstrom et al reported the number of binges in the last 90 days, both of them showing no significant differences 


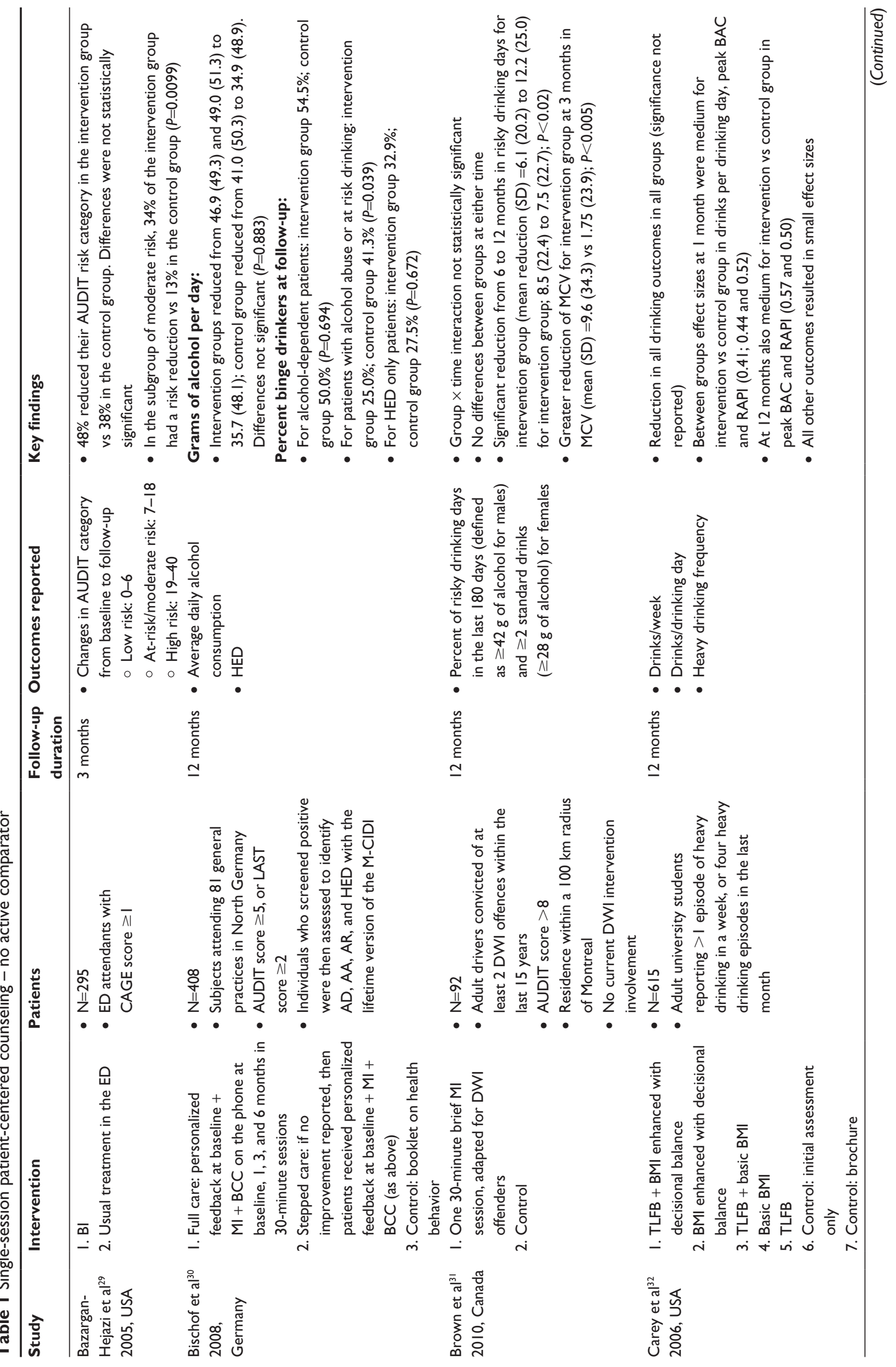




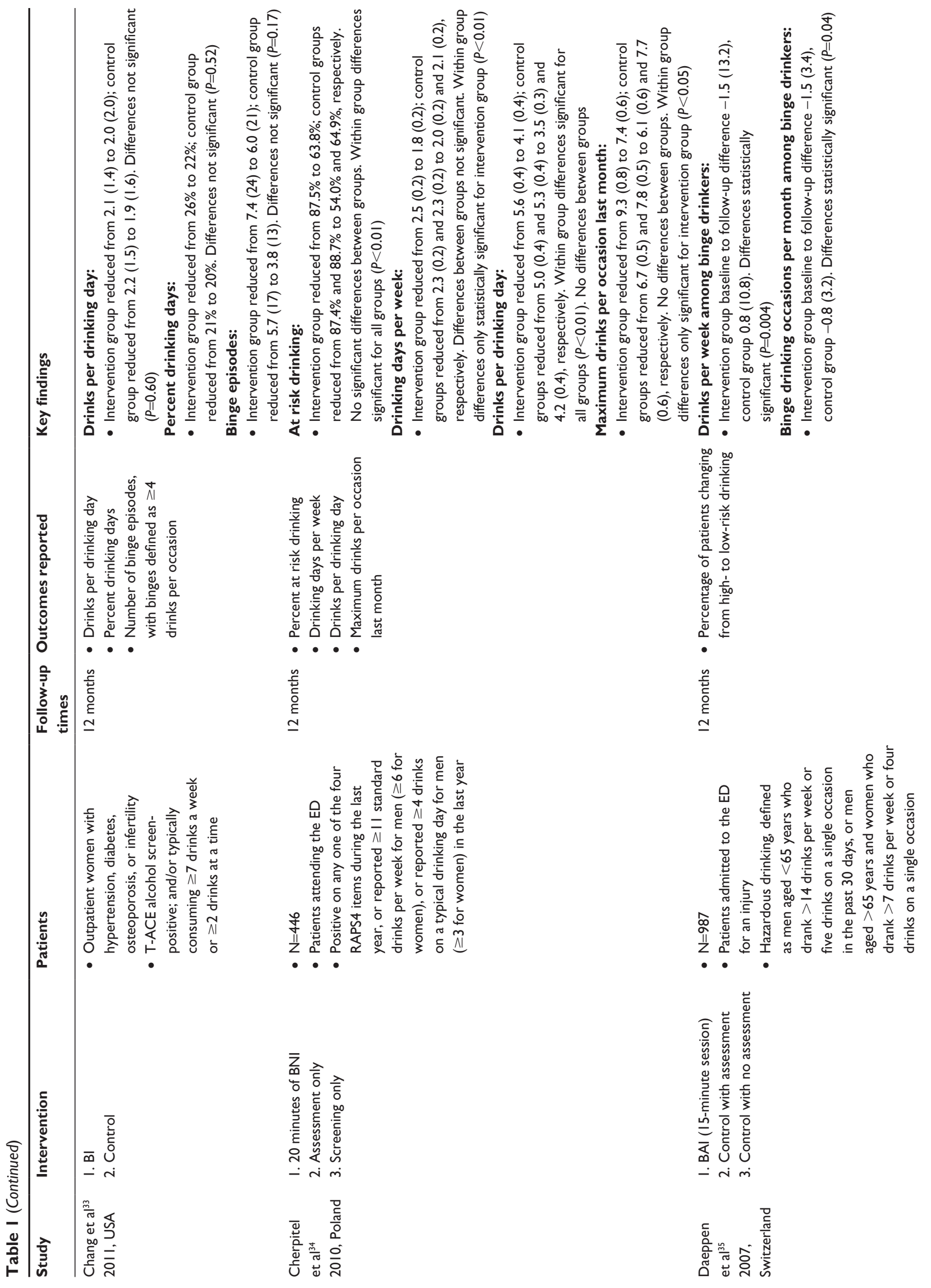




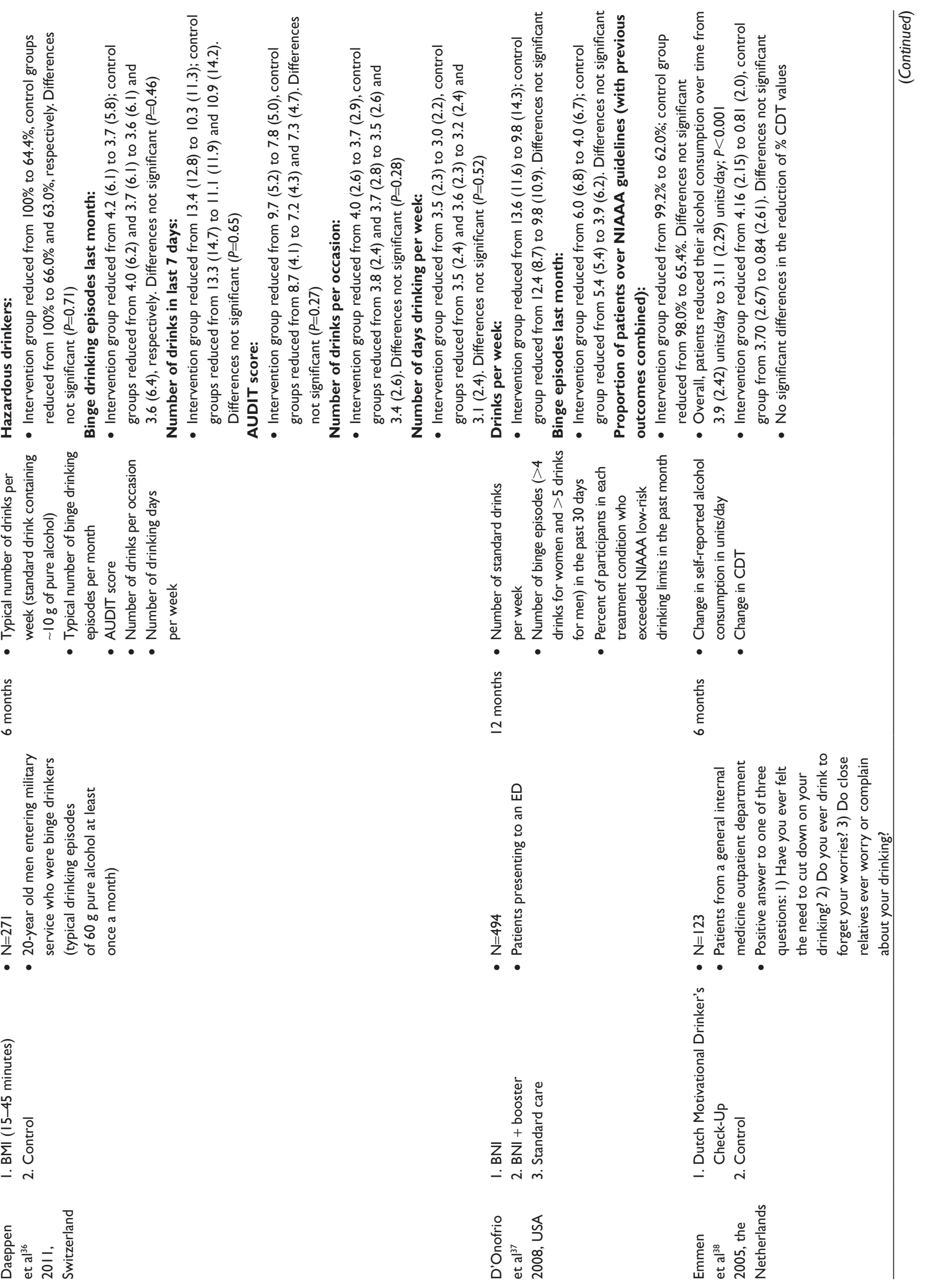




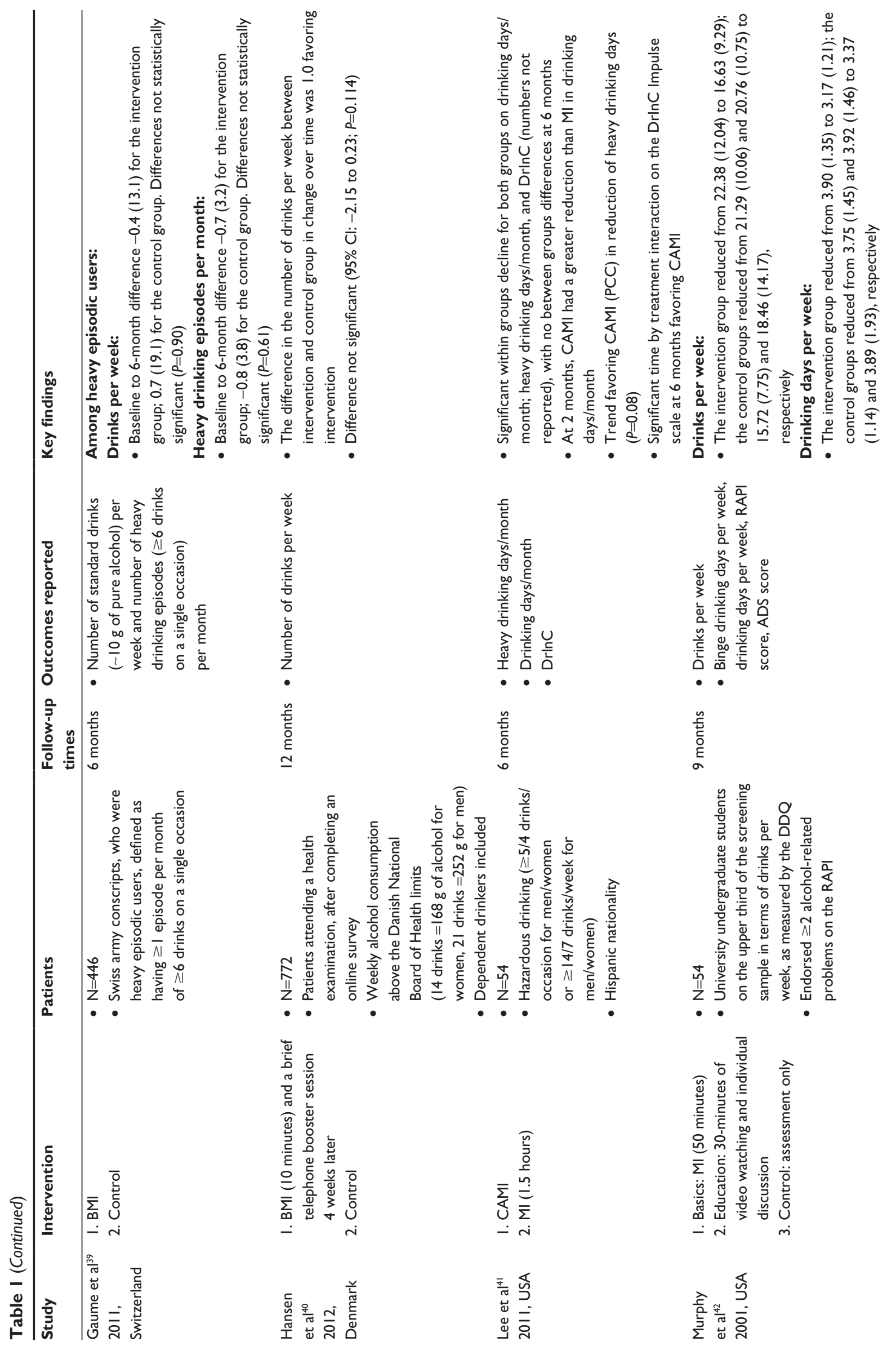




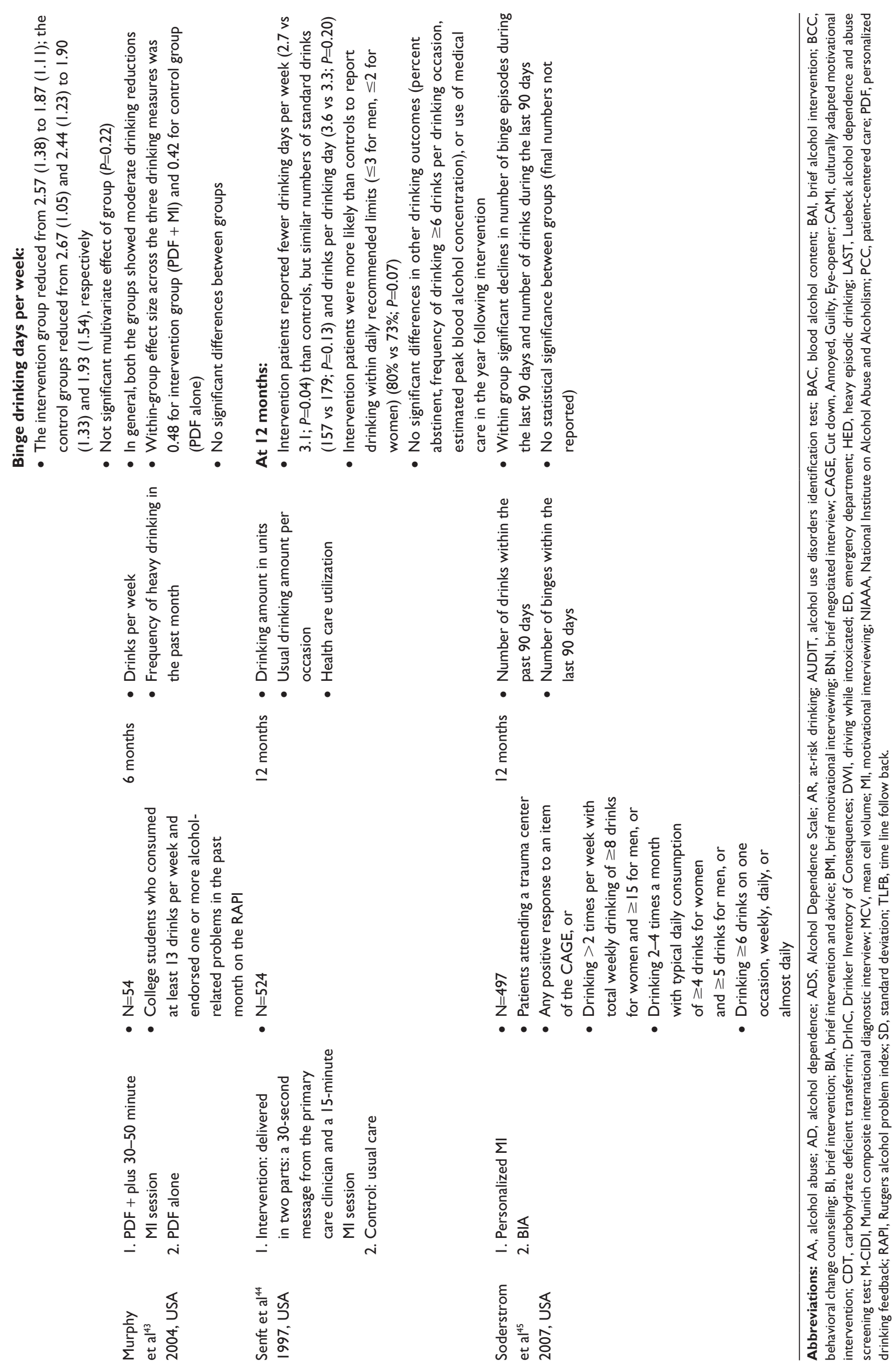


between groups. ${ }^{43,45}$ Brown et al (2007) reported a significant difference only for men in the reduction in number of risky drinking days (30\% vs $12.9 \%$, significance not reported), ${ }^{31}$ and Senft et al found no differences in the frequency of risky drinking. ${ }^{44}$

Three studies reported the percentage of heavy drinkers at study end. Two could not find any significant difference, ${ }^{35,37}$ while the remaining study by Bischof et al reported a statistically significant difference only in the subgroup of patients with alcohol abuse $(25 \%$ vs $41.3 \% ; P=0.039)$, with no difference in the alcohol-dependent or heavy episodic drinking-only subgroups. ${ }^{30}$ Cherpitel et al reported a nonsignificant difference in the percentage of at risk drinkers between groups or in the maximum number of drinks per occasion. ${ }^{34}$ Carey et al reported a medium effect size in peak blood alcohol favoring the PCC group (significance not reported), ${ }^{32}$ while Senft et al reported no significant difference in this outcome. ${ }^{44}$

\section{Scores}

Bazargan-Hejazi et al reported a nonsignificant difference in the percentage of patients changing their drinking risk status according to the Alcohol Use Disorders Identification Test (AUDIT) score. ${ }^{29}$ In the subgroup of moderate risk (scores $7-18$ ), the PCC group had a larger reduction (34\% vs $13 \%$; $P=0.0099)$. Daeppen et al reported a nonsignificant difference between groups regarding the change in the AUDIT score. $^{35}$

\section{More than one session PCC with no active comparator}

Fifteen studies were included in this subgroup (Table 2). ${ }^{46-60}$ Taken together, data show mixed results, with some studies reporting significant differences between groups, whereas others do not.

\section{Amount and frequency of alcohol consumption}

Nine studies reported data regarding the amount of alcohol consumption. Five studies reported it in the form of units of alcohol per week. ${ }^{49,51,52,57,58}$ Two failed to show statistically significant differences between groups, ${ }^{49,51}$ while the other three reported significant differences for the intervention groups. ${ }^{52,57,58}$ The amount of alcohol consumption in the two intervention groups in D'Onofrio et al decreased from 20.4 and 19.8 to 13.0 and 14.3 , respectively, while that in the control group ranged from 20.9 to $17.6(P=0.045) .^{52}$ The reductions in Monti et al for the intervention and the control group were $13.07-6.10$ and $10.77-8.83$, respectively $(P<0.01$ in the treatment $\times$ time interaction $) .{ }^{57}$ Noknoy et al reported decreases from 13.27 to 4.72 and from 10.55 to 11.24 for the intervention and control group, respectively $(P=0.04) .{ }^{58}$ Maisto et al reported significant decreases for brief interventions but not for $\mathrm{MI}$ in the number of drinks in the past month. ${ }^{55}$

Two studies reported on the amount of grams of alcohol per week, ${ }^{46,47}$ with no significant differences between groups at study end. These two studies also reported on the number of drinks per drinking day, again failing to reach any significant difference between groups. Noknoy et al also reported on this outcome, finding a statistically significant difference at 6 months follow-up favoring the PCC group (2.26 vs 4.02; $P=0.018){ }^{58}$

Finally, five studies reported on the number of days drinking. Three of them failed to find any significant difference, ${ }^{46,47,55}$ whereas Monti et al reported a significant difference in the time $\times$ treatment interaction favoring the PCC group (4.52 vs 6.54 in the last month; $P<0.001) .{ }^{57}$ Sellman et al reported no difference regarding the percentage of abstinent patients. ${ }^{59}$

\section{Hazardous and heavy drinking}

Ten studies reported outcomes related to heavy or hazardous drinking. Curry et al reported a 19\% difference between groups in the proportion of patients reporting any at risk drinking pattern, favoring the PCC group (42\% vs $61 \%$; $P=0.003) .{ }^{51}$ Allen et al failed to show any significant difference on the same outcome. ${ }^{48}$ Sellman et al reported a significant decrease in the percentage of heavy drinking days in the past 6 months favoring PCC (42.9\% vs 65\%). ${ }^{59}$

Sommers et al and Beich et al reported on the relative risk of heavy drinking between groups. Although differences favored the PCC group, they were not statistically significant at study end. ${ }^{49,60}$

Three studies reported on the number of risky drinking days in the last month. Brown et al did not find any significant difference, ${ }^{50}$ whereas the other two reported statistically significant differences favoring the PCC groups. D'Onofrio et al reported a decrease from 7.5 and 7.2 to 4.7 and 5.1 versus a decrease from 7.2 to $5.8(P=0.03) .{ }^{52}$ Monti et al reported a statistically significant difference in the treatment $\times$ time interaction (4.52 versus $6.54 ; P<0.001) .{ }^{57}$ Longabaugh et al found no significant difference in the number of heavy drinking days between groups. ${ }^{54}$

Noknoy et al reported on the number of binge episodes in the last week, with no significant differences between groups, ${ }^{58}$ and Sommers et al reported on the maximum units of alcohol in a 6-hour period, with no significant differences between groups at study end. ${ }^{60}$ 


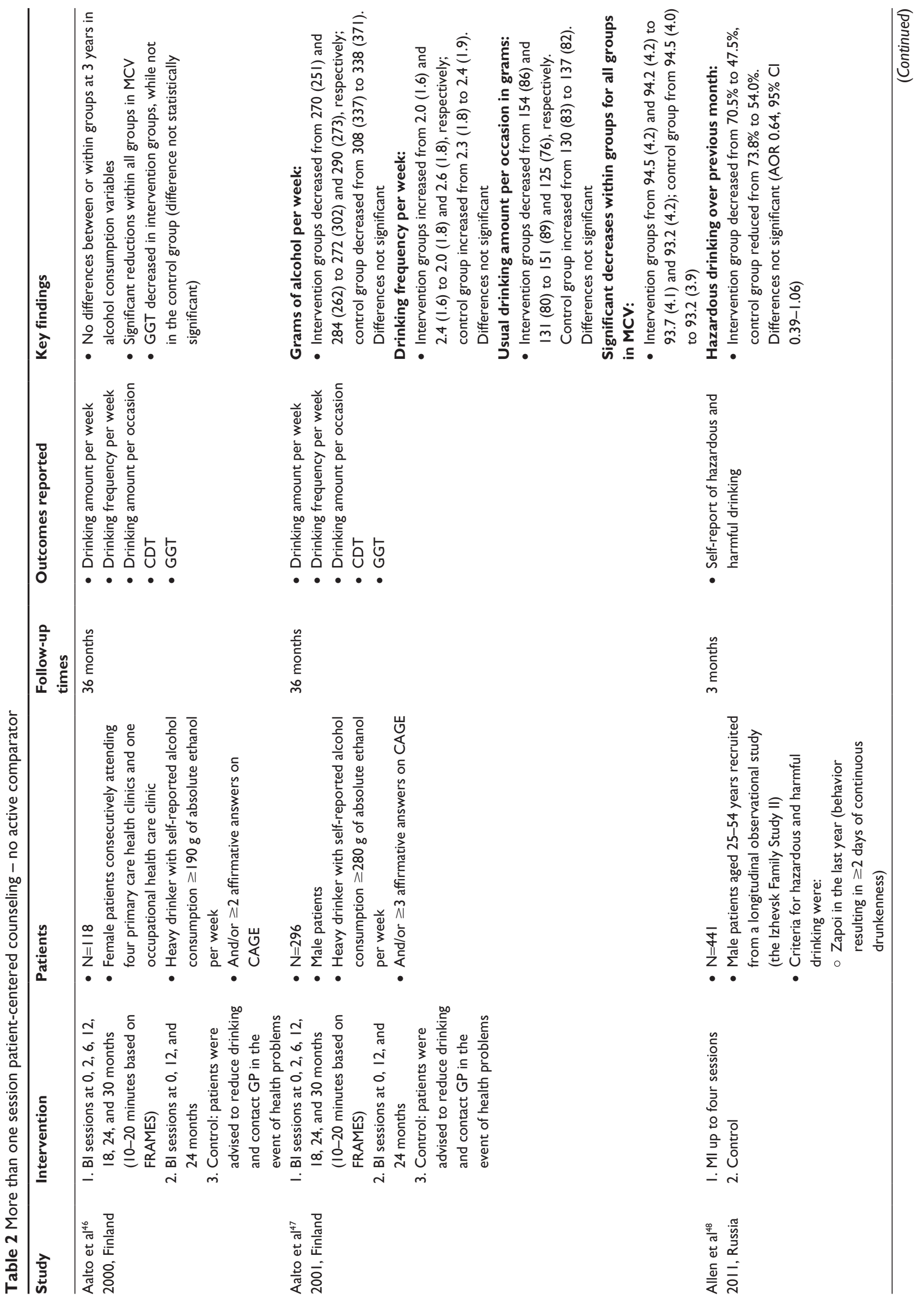




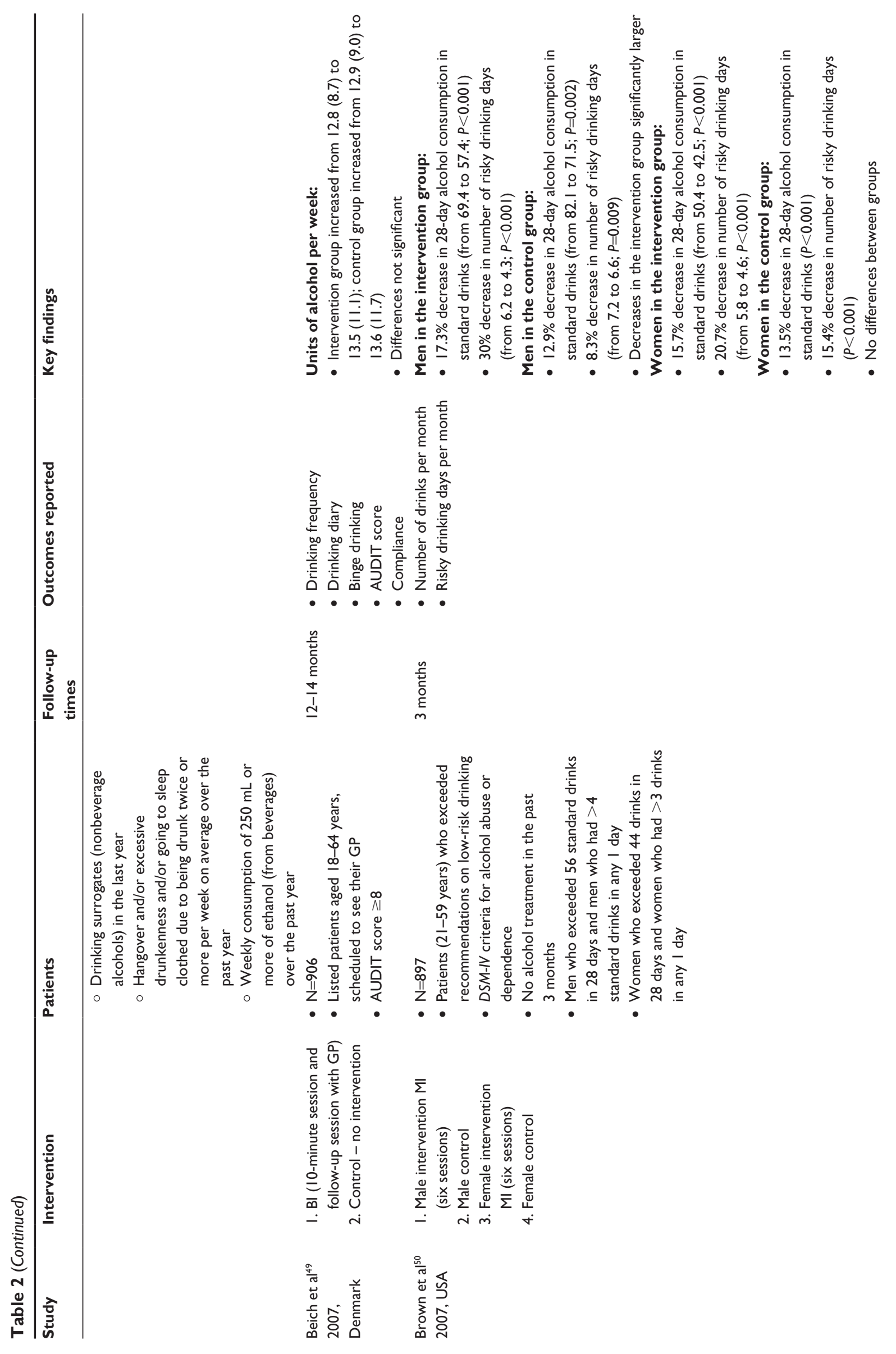



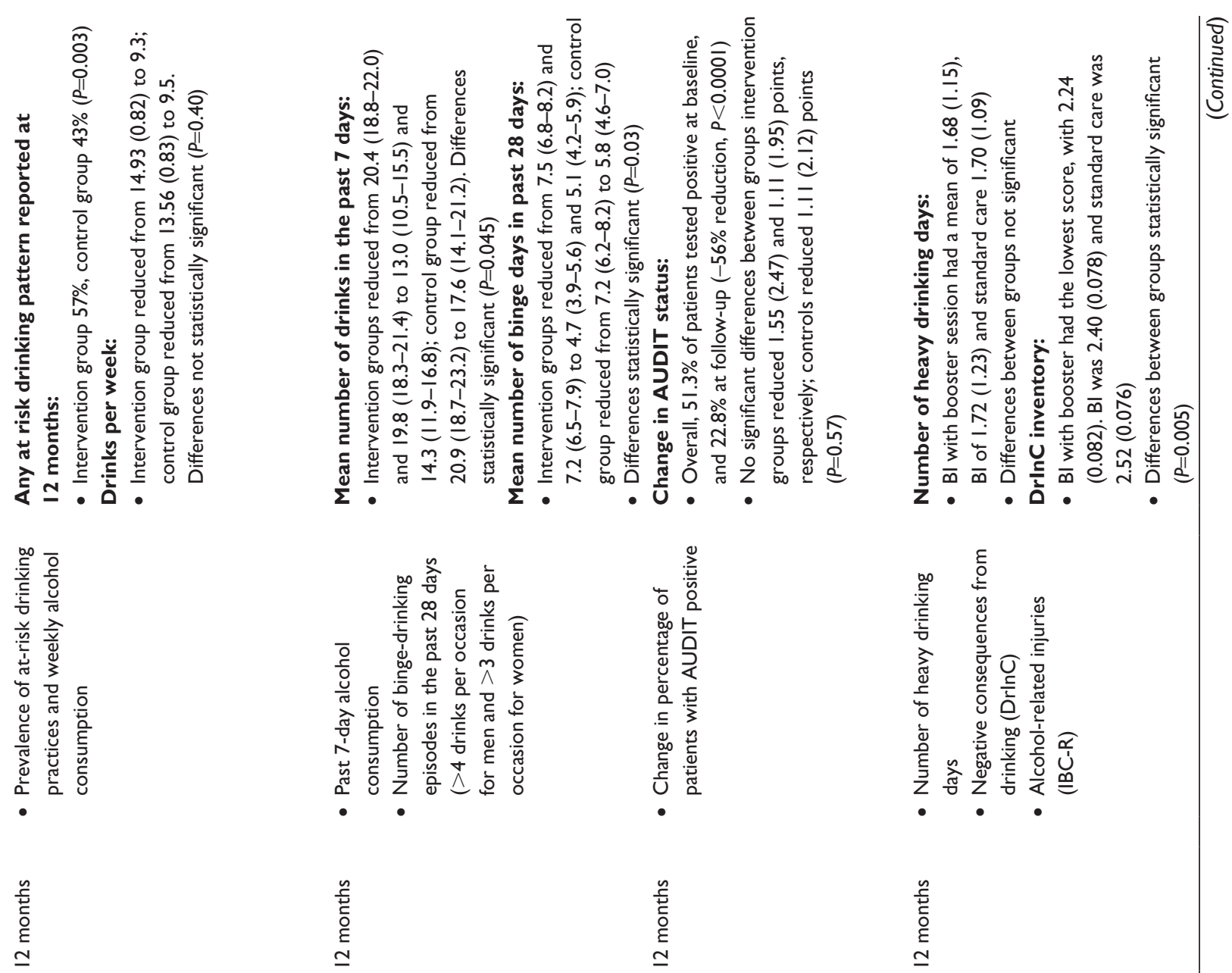

$\stackrel{n}{+}$
$\stackrel{5}{c}$
$\stackrel{1}{E}$
$\simeq$

$\stackrel{n}{+}$
$\stackrel{0}{0}$
$\Xi$
$\simeq$
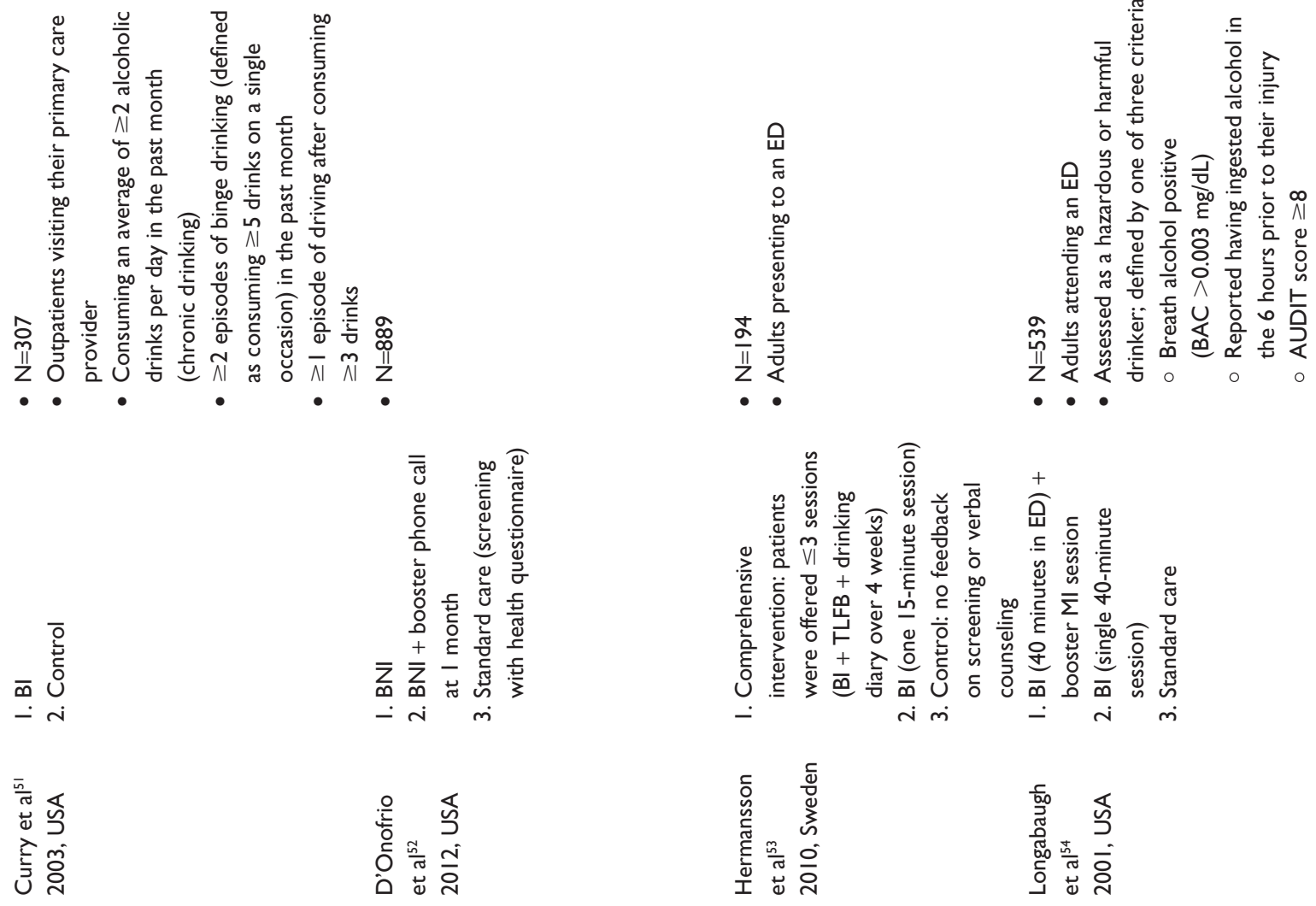


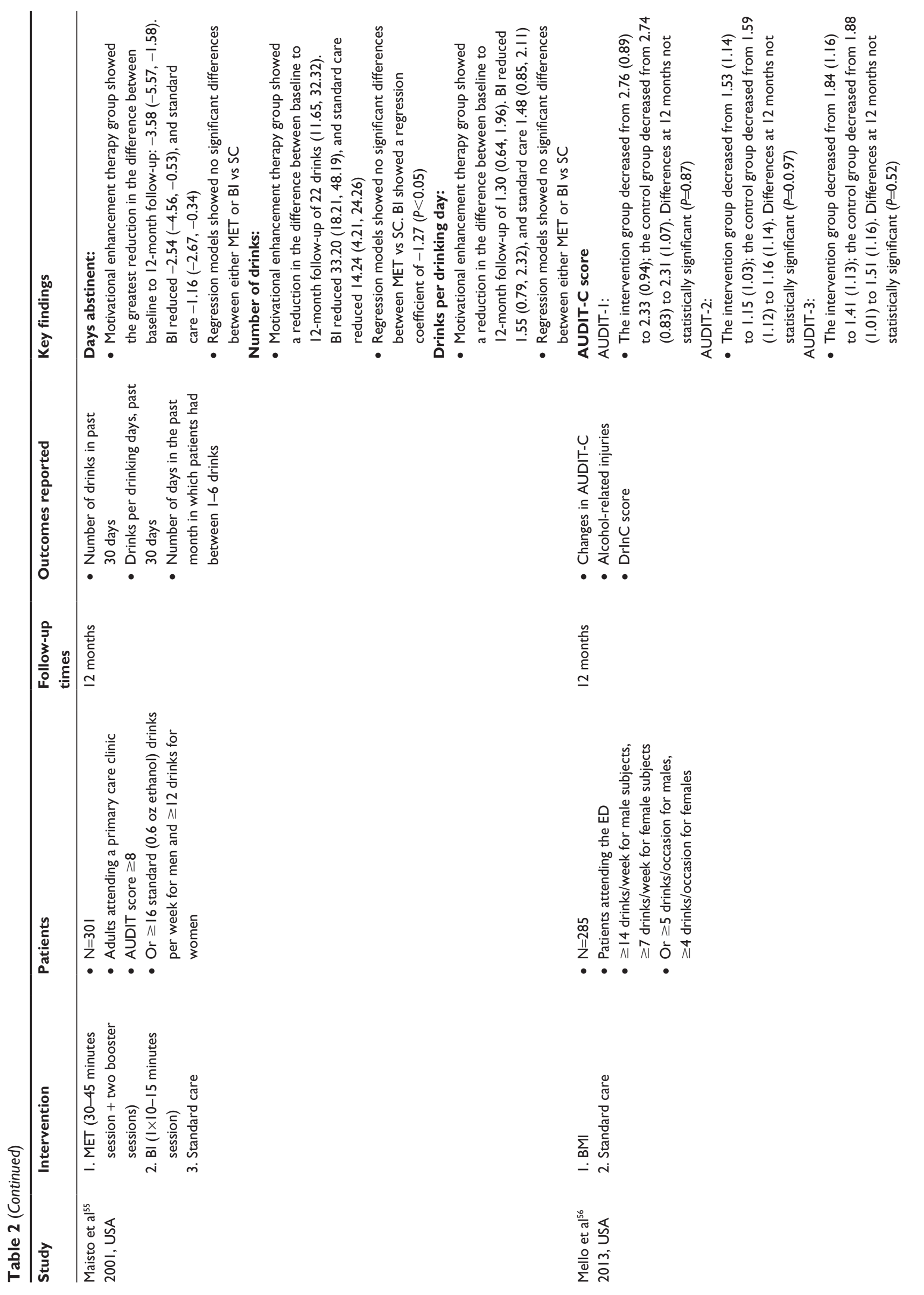




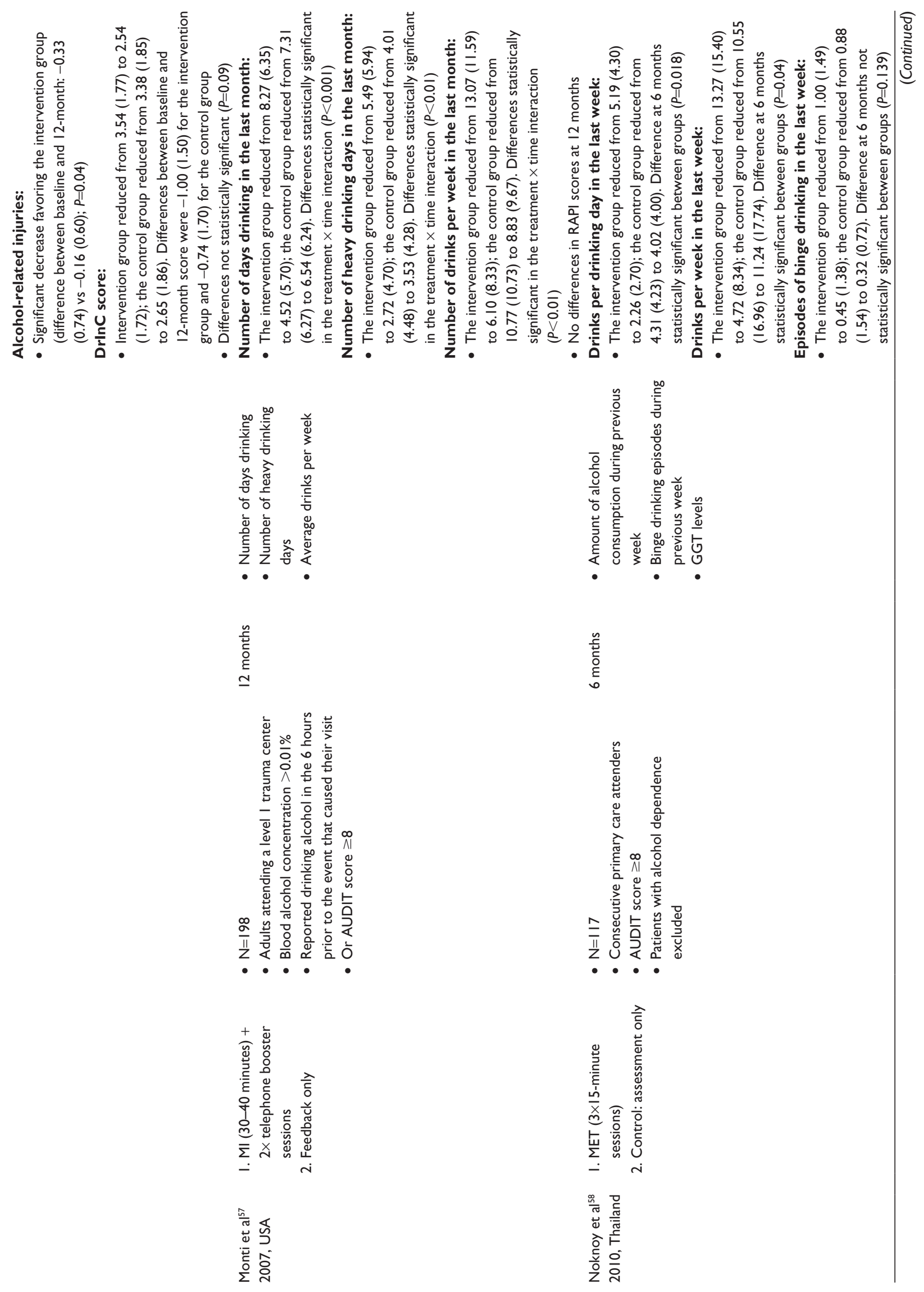




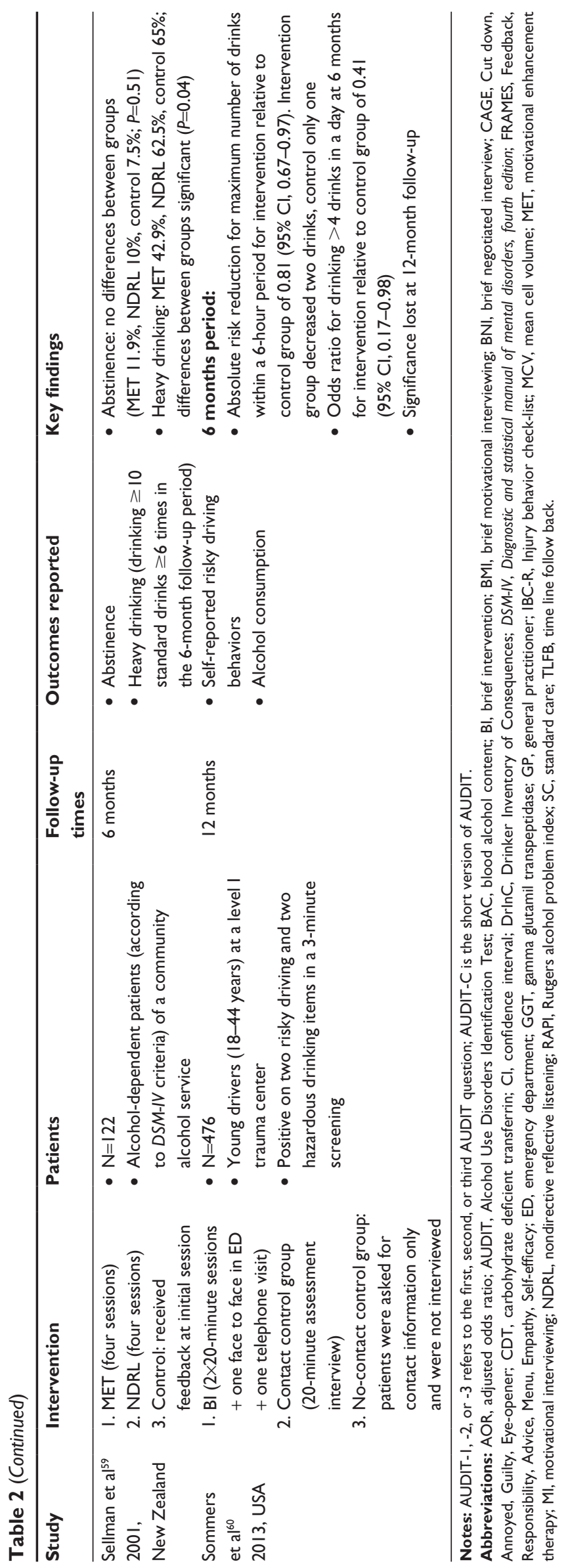

\section{Alcohol scores}

Two studies reported no significant changes in AUDIT or AUDIT-C scores between groups. ${ }^{53,56}$ Hermansson et al reported a significant decrease for the whole sample in the AUDIT score. ${ }^{53}$

\section{PCC - active comparator}

Three studies were included in this subgroup (Table 3) ${ }^{61-63}$ Patient-centered counseling strategies, mainly through MI, where compared against CBT and 12 steps facilitation in one study, ${ }^{61}$ against CBT in another, ${ }^{63}$ and against social behavioral network therapy in the other. ${ }^{62}$ Taken together, data from these studies suggest that all these counseling strategies are effective in the treatment of alcohol use disorders, with no significant differences between any of them.

\section{Amount and frequency of alcohol consumption}

The three studies failed to report a significant difference between groups while measuring outcomes related to alcohol consumption. Two reported on number of drinks per drinking day, with no significant differences between groups, although globally the whole study sample improved significantly (in the UK Alcohol Treatment Trial study, eg, the reduction was from 26.8 to 19.2). ${ }^{61,62}$ The same two studies reported also on percentage of days abstinent, with the same general improvement, with no group significant differences (again, in the UK Alcohol Treatment Trial study, it changed from $29.5 \%$ to $46.0 \%$ for the whole sample). The study by Shakeshaft et al reported a significant within PCC group decrease in the number of drinks per week (from 32.7 to $24.9 ; P<0.01$ ), with no statistically significant differences when compared to $\mathrm{CBT}{ }^{63}$

\section{Hazardous and heavy drinking}

Two studies reported on measures related to heavy drinking. . $^{61,63}$ Project MATCH (Matching Alcoholism Treatments to Client Heterogeneity) reported a statistical superiority of 12 steps facilitation against CBT and motivational enhancement therapy in the survival analysis in relapse to heavy drinking (defined as three consecutive days of $>5$ drinks per day for men and $>3$ drinks per day for women), where $53 \%$ of 12 steps facilitation patients did not relapse, and $49 \%$ and $48 \%$ in the motivational enhancement therapy and CBT groups did not relapse. ${ }^{61}$ Shakeshaft et al reported a significant within PCC group decrease in heavy drinking episodes in the last 30 days (from 20.9 to $15.4 ; P<0.01$ ). Again, no statistically significant differences were noted between groups. ${ }^{63}$

\section{Patient-centered pharmacological interventions}

Five studies were classified in this group (Table 4). ${ }^{64-68}$ They all shared the same strategy: targeted or as-needed 


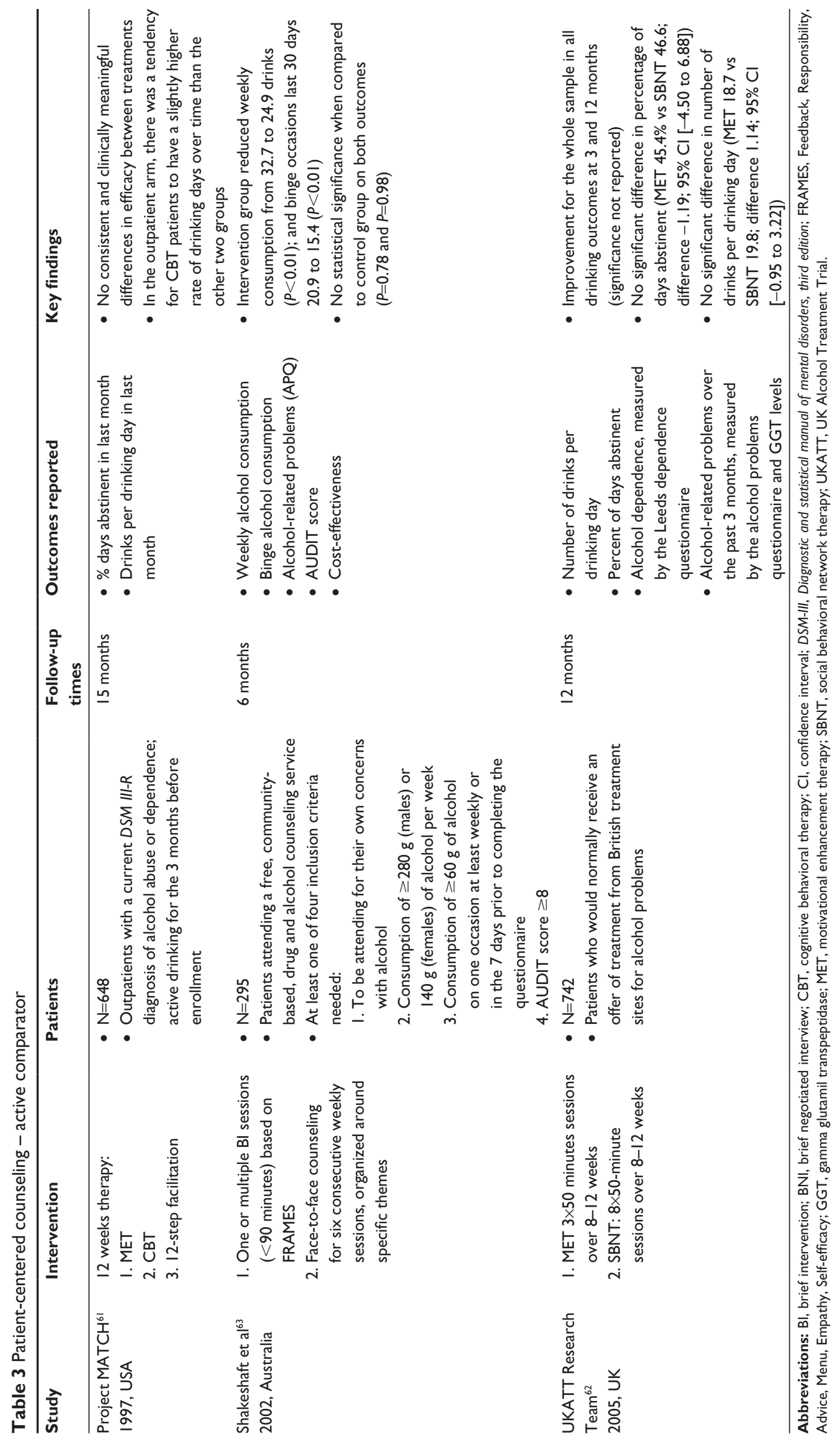


medication. Three used nalmefene as the study medication, and two used naltrexone. Overall, data clearly suggest a benefit of the PCC intervention, when compared with the control groups, in terms of reduction in alcohol consumption and heavy drinking, with most of the differences reaching statistical significance.

\section{Amount and frequency of alcohol consumption}

Four of the five studies in this group reported statistically significant reductions in the intervention group when compared with the control. Mann et al found a significant reduction in grams per day for the nalmefene group (-50.7 vs -39.7). ${ }^{64}$ Heinala et al reported a significant difference in grams/week when comparing the coping-naltrexone group with the rest combined (231 vs 354, 357, and 326; $P=0.05)$. ${ }^{67}$ Karhuvaara et al reported statistically significant differences in both drinks per week and drinks per drinking day favoring the targeted nalmefene group (drinks per week in the last month: 23.2 vs $28.5, P=0.0018$; drinks per drinking day in the last month: 6.3 vs $7.3, P=0.0134) .{ }^{66}$ Kranzler et al reported the targeted naltrexone group drinking $16.5 \%$ less than the other groups, although differences were not statistically significant. ${ }^{68}$ However, among men at week 12, the differences did reach significance $(P=0.027)$. The remaining study by Gual et al reported a baseline to 6-month difference of $-5.0 \mathrm{~g} /$ day favoring the PCC group, but it did not reach statistical significance $(95 \% \mathrm{CI}-10.6$ to $0.7 ; P=0.08) .{ }^{65}$

\section{Hazardous and heavy drinking}

The four studies assessing this outcome (Heinala et al, 2001, Karhuvaara et al, 2007, Mann et al, 2013, and Gual et al, 2013) reported statistically significant differences in heavy drinking favoring the PCC groups. ${ }^{64-67}$ The 6-month differences in heavy drinking days per month reported by Gual et al and Mann et al were -1.7 days/month (95\% CI -3.1 to 0.4 ; $P=0.012)$ and -2.3 days/month $(P=0.0021)$, respectively, both favoring the nalmefene group. ${ }^{64,65}$ In the study by Heinala et al, the targeted naltrexone group combined with nonabstinenceoriented group therapy did better than the others in survival analysis for preventing relapse to heavy drinking, reaching statistical significance (exact numbers not reported). ${ }^{67}$ Karhuvaara et al reported a statistically significant decrease in heavy drinking days per month favoring the targeted nalmefene group (from 15.5 to 8.8 vs 16.2 to $10.6 ; P=0.0065$ ). ${ }^{66}$

\section{Discussion}

In this paper, we systematically reviewed the efficacy of interventions based on a PCC health care approach for the management of alcohol use disorders. When reviewing the studies identified by our search, it was realized that all PCC trials selected for the review could easily be categorized into two groups: psychosocial interventions and pharmacological supported interventions, and hence, this grouping was adopted. Psychosocial interventions could then be classified further into single sessions of PCC and multiple sessions of PCC.

Regarding psychosocial interventions, our results are in line with previous systematic reviews conducted specifically for MI, which, as mentioned earlier, was the cornerstone of PCC psychosocial interventions found in this review. ${ }^{28,71}$ Findings within the categories of trials on PCC interventions based on MI appeared mixed. If differences in alcohol consumption emerged between intervention and control groups, they were usually not significant if participants attended one counseling session only. The proportion of studies suggesting that PCC is more effective than control interventions increased if participants took part in several counseling sessions; that is, the number of counseling sessions seems to moderate the effectiveness of PCC. This is in line with the finding of a previous systematic review which concluded that PCC interventions of more than one session work by first increasing the patients' readiness to change during the first session, and then effecting reduction in alcohol consumption in the follow-up sessions. ${ }^{28}$

Regarding pharmacologically supported PCC interventions, based on the as needed approach, an effect seemed to emerge from our review. However, the effect cannot be attributed fully to pharmacological elements, since studies in this group also had a psychosocial component, and therefore interactions between the two should be taken into account when interpreting the findings. Considering the fact that only a very small percentage of patients with alcohol use disorders $(<10 \%)$ receive treatment, ${ }^{72,73}$ this finding has significant implications for current health care. All the studies of pharmacological interventions were included in this review on the basis of their "as needed" use. This paradigm has been controversial in addiction medicine for many years, with many believing that medications for alcohol use disorders need to be taken on a supervised, strict basis. In this respect, a recent analysis of clinical trial data for nalmefene concluded that people with alcohol dependence are able to adhere to an as needed regimen. ${ }^{68}$ The data indicate that medication intake varies according to drinking patterns with some patients taking the medication daily and others taking medication at tailored intervals. In their recent editorial, Bradley and Kivlahan ${ }^{2}$ suggested that pharmacological 


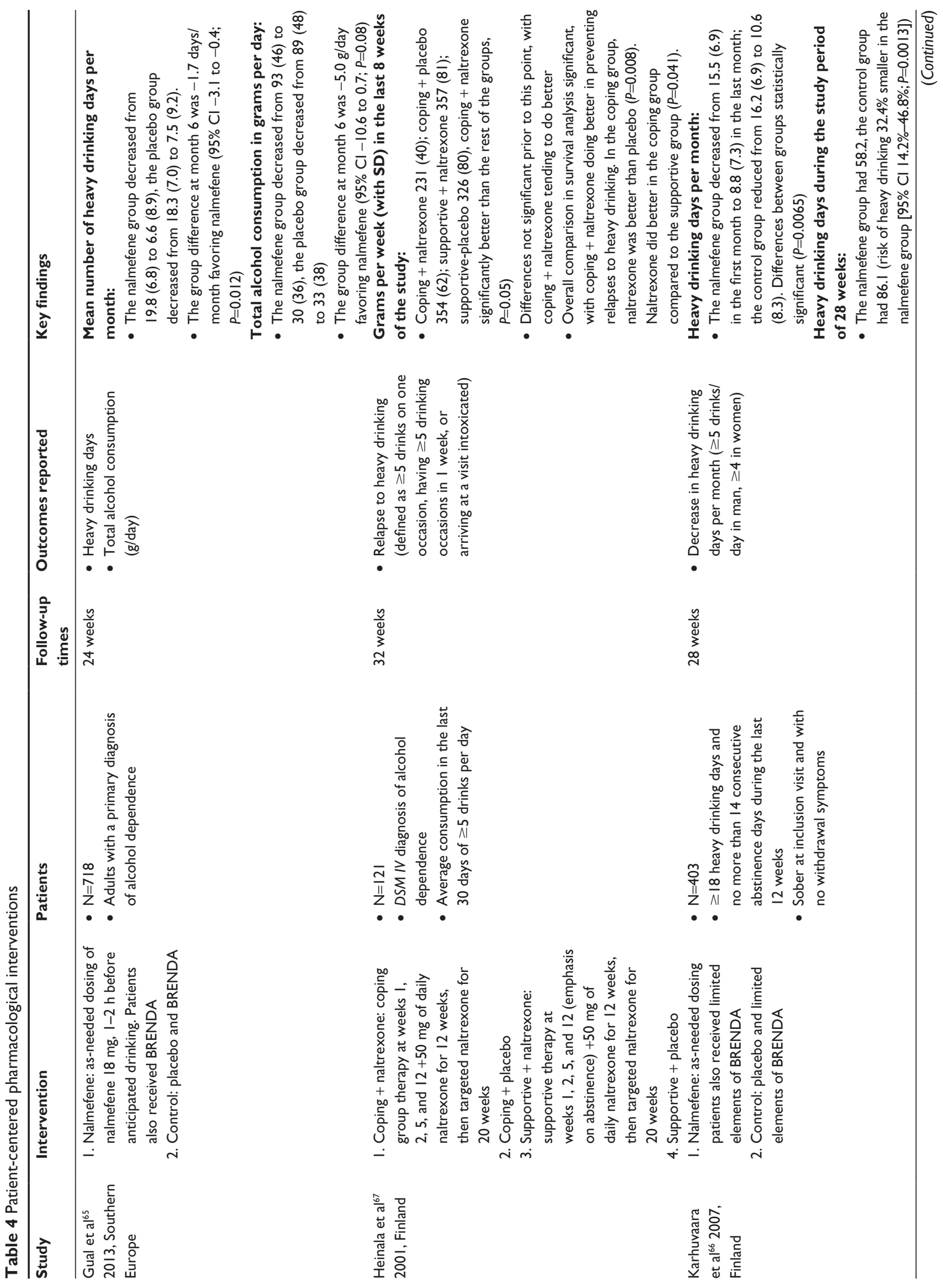




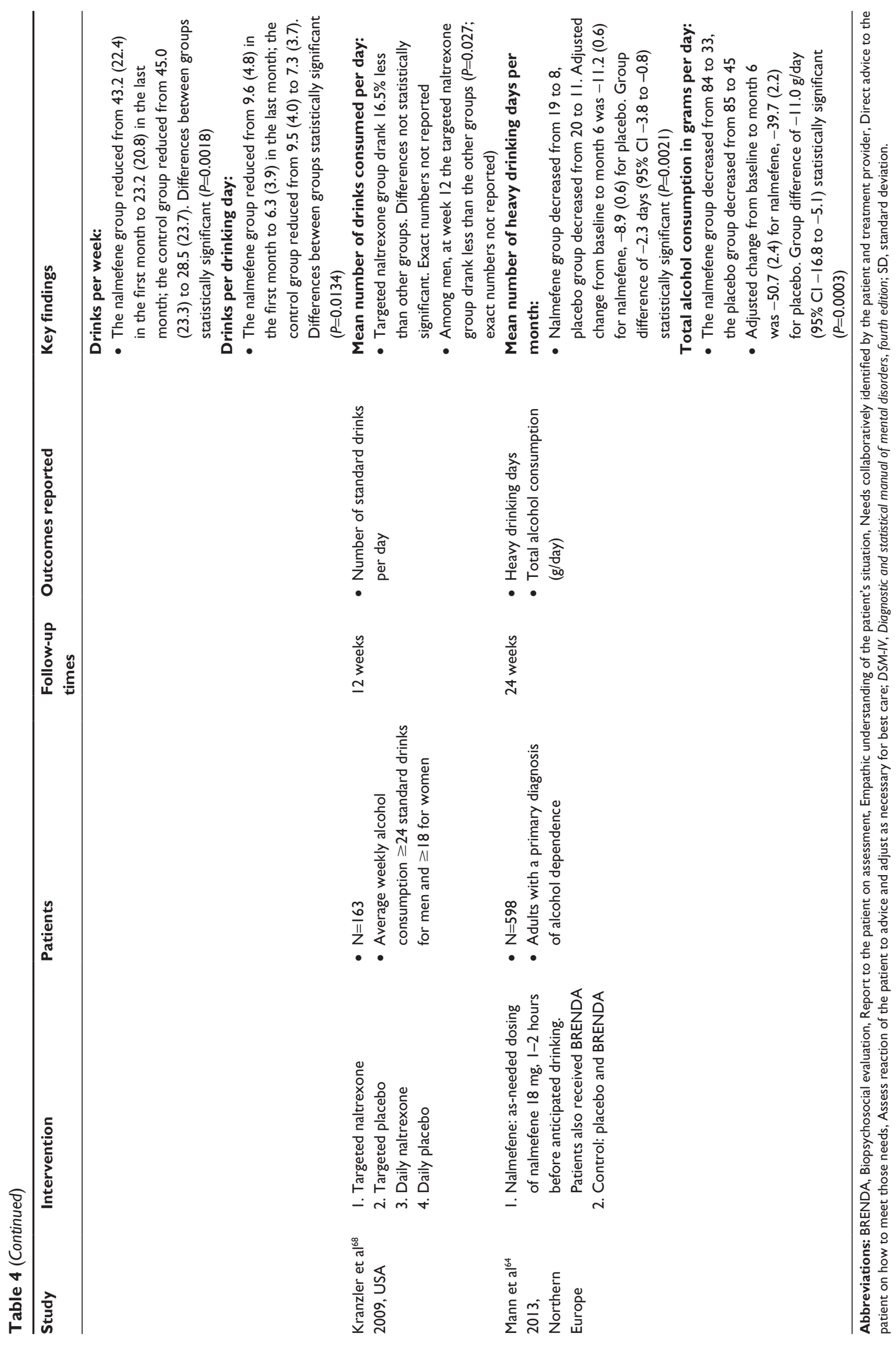


interventions might help bring the concepts of PCC into the alcohol field. By understanding that effective treatments are available, health care professionals are better able to offer people with alcohol use disorders various evidence-based options, including medications and psychosocial support, to achieve recovery.

A key difficulty in conducting this review was the definition and operationalization of PCC as a concept that translates into alcohol use disorders. PCC is not a binary concept (present or absent), and the potential alcohol interventions had to be judged along a continuum of PCC interventions. Despite this fact, we had to simplify and finally dichotomize interventions as PCC or not PCC. For example, the efficacy of pharmacologically supported interventions was considered a key component of this research. Although medications are not PCC (they are just chemical compounds), as needed use allows them to be prescribed in accordance with the principles of PCC. Conversely, computerized interventions were not included in this review. Although one might argue that they can also be considered PCC depending on how they are structured and conducted, they are ultimately based on a predefined number of algorithms and options, thus making it difficult to truly individualize the intervention according to the needs of each patient.

The considerable heterogeneity of the studies included made it impractical to perform any meta-analyses of the data, and so we were limited to narrative descriptions. As discussed by the authors of other systematic reviews of alcohol interventions, this will remain a barrier until consensus is reached in the preferred methods for measuring alcohol consumption. ${ }^{28,71,74}$ It is therefore important to note that the European Medicines Agency now recommends total alcohol consumption and the number of heavy drinking days as suitable outcomes for studies of alcohol reduction as well as the continued abstinence rate for studies where abstinence is the stated goal. It further suggests that total alcohol consumption and heavy drinking days can also be used to assess the impact of an abstinence-based intervention when patients have a relapse (or lapse or slip). ${ }^{17}$ It is hoped that such guidance will aid the future standardization of studies.

Other potential limitations of our review include the broad definition of alcohol use disorders (hazardous or harmful drinking, alcohol dependence, or any other alcohol use disorder) and the consequent inclusion of patients with and without a diagnosis of alcohol dependence. It may be that patients with dependence require longer periods of interventions than those without dependence, and this factor might have contributed to some of the findings, especially for PCC psychosocial interventions. To try and homogenize the review, we did not include studies of patients with psychiatric comorbidities or with relevant and differential characteristics (eg, mandated or incarcerated patients and pregnant women). Although necessary for the purposes of this review, application of these exclusion criteria resulted in the exclusion of a number of potentially interesting studies. For example, one large long-term study with nalmefene ${ }^{75}$ was excluded because it included patients taking antipsychotics or antidepressants for current psychiatric comorbidities. Also, it is important to remark that an important share of alcohol patients do suffer from negative emotional and affective states that might indeed be produced by alcohol itself. Therefore, this exclusion might have oversimplified a complex reality such as the one of alcohol use disorders. Finally, the external validity of our findings is handicapped by the fact that male patients were more than twice as frequent as females in all the categories.

\section{Conclusion}

The limitations of the review, as well as the mixed results found in some of the categories investigated, prevent firm conclusions to be drawn. Single-session studies did not appear to show a clear benefit, multiple-session studies showed mixed results, and active comparator studies did not report significant differences while measuring outcomes related to alcohol consumption. Although pharmacological studies were found the most robustly effective, the shorter follow-up periods and the concomitant presence of psychosocial components in the studies prevent a full and clear attribution to be done. However, since we believe that PCC is increasingly accepted as a central tenet of highquality health care, and some of the results of this review suggest PCC could indeed be an appropriate strategy for alcohol use disorders, there is an urgent need for additional research evidence on the effectiveness of PCC-based alcohol interventions.

\section{Acknowledgments}

$\mathrm{H}$ Lundbeck A/S funded this systematic review. The authors were solely responsible for the collection, analysis, and interpretation of data and in the writing of the report. There was no payment for the writing of the report, and the decision to submit the report for publication also rested with the authors. The authors thank Anita Chadha-Patel (ACP Clinical Communications Ltd. funded by $\mathrm{H}$ Lundbeck A/S) for editorial assistance (English language editing and referencing). 


\section{Disclosure}

The authors report no conflicts of interest in this work.

\section{References}

1. Institute of Medicine, Committee on Quality of Health Care in America. Crossing the Quality Chasm: A New Health System for the 21st Century. Washington, DC: National Academy Press; 2001.

2. Bradley KA, Kivlahan DR. Bringing patient-centered care to patients with alcohol use disorders. JAMA. 2014;311:1861-1862.

3. Rathert C, Wyrwich MD, Boren SA. Patient-centered care and outcomes: a systematic review of the literature. Med Care Res Rev. 2013; 70(4):351-379.

4. Lusk JM, Fater K. A concept analysis of patient-centered care. Nurs Forum. 2013;48(2):89-98.

5. Appelbaum PS. Clinical practice. Assessment of patients' competence to consent to treatment. $N$ Engl J Med. 2007;357:1834-1840.

6. Roberts LW. Informed consent and the capacity for voluntarism. Am J Psychiatry. 2002;159:705-712.

7. Coverdale JH, Chervenak FA, McCullough LB, Bayer T. Ethically justified clinically comprehensive guidelines for the management of the depressed pregnant patient. Am J Obstet Gynecol. 1996;174:169-173.

8. McCullough LB, Coverdale JH, Chervenak FA. Ethical challenges of decision making with pregnant patients who have schizophrenia. $\mathrm{Am}$ J Obstet Gynecol. 2002;187:696-702.

9. Goossensen A, Zijlstra P, Koopmanschap M. Measuring shared decision making processes in psychiatry: skills versus patient satisfaction. Patient Educ Couns. 2007;67:50-56.

10. Goss C, Moretti F, Mazzi MA, Del Piccolo L, Rimondini M, Zimmermann C. Involving patients in decisions during psychiatric consultations. Br J Psychiatry. 2008;193:416-421.

11. Cox K, Stevenson F, Britten N, Dundar Y. A systematic review of communication between patients and health care professionals about medicine-taking and prescribing. King's College London, GKT Concordance Unit, Guys' King's and St Thomas' School of Medicine. 2003. Available from: www.medicines-partnership.org. Accessed December 1, 2015.

12. Swanson KA, Bastani R, Rubenstein LV, Meredith LS, Ford DE. Effect of mental health care and shared decision making on patient satisfaction in a community sample of patients with depression. Med Care Res Rev. 2007;64:416-430.

13. Lim SS, Vos T, Flaxman AD, et al. A comparative risk assessment of burden of disease and injury attributable to 67 risk factors and risk factor clusters in 21 regions, 1990-2010: a systematic analysis for the Global Burden of Disease Study 2010. Lancet. 2013;380:2224-2260.

14. Anderson P, Braddick F, Reynolds J, Gual A, editors. Alcohol policy in Europe: Evidence from AMPHORA. 2nd ed. The AMPHORA project. 2013. Available from: http://amphoraproject.net/view.php?id_cont $=45$. Accessed December 1, 2015.

15. Anderson P, Wojnar M, Jakubczyk A, et al. Managing alcohol problems in general practice in Europe: results from the European ODHIN survey of general practitioners. Alcohol Alcohol. 2014;49:531-539.

16. Rehm J, Anderson P, Barry J, et al. Prevalence of and potential influencing factors for alcohol dependence in Europe. Eur Addict Res. 2015; 21:6-18.

17. EMA. Guideline on the development of medicinal products for the treatment of alcohol dependence. EMA/CHMP/EWP/20097/2008 (previously EMEA/CHMP/EWP/20097/2008). 2010. Available from: http://www.ema.europa.eu/docs/en_GB/document_library/ Scientific_guideline/2010/03/WC500074898.pdf. Accessed December $1,2015$.

18. Gastfriend DR, Garbutt JC, Pettinati HM, Forman RF. Reduction in heavy drinking as a treatment outcome in alcohol dependence. $J$ Subst Abuse Treat. 2007;33:71-80.

19. Sanchez-Craig M, Annis HM, Bornet AR, MacDonald KR. Random assignment to abstinence and controlled drinking: evaluation of a cognitive-behavioral program for problem drinkers. J Consult Clin Psychol. 1984;52:390-403.
20. Ambrogne JA. Reduced-risk drinking as a treatment goal: what clinicians need to know. J Subst Abuse Treat. 2002;22:45-53.

21. Heilig M, Goldman D, Berrettini W, O’Brien CP. Pharmacogenetic approaches to the treatment of alcohol addiction. Nat Rev Neurosci. 2011; 12:670-684.

22. Luquiens A, Reynaud M, Aubin HJ. Is controlled drinking an acceptable goal in the treatment of alcohol dependence? A survey of French alcohol specialists. Alcohol Alcohol. 2011;46:586-591.

23. Al-Otaiba Z, Worden BL, McCrady BS, Epstein EE. Accounting for self-selected drinking goals in the assessment of treatment outcome. Psychol Addict Behav. 2008;22:439-443.

24. Hodgins DC, Leigh G, Milne R, Gerrish R. Drinking goal selection in behavioral self-management treatment of chronic alcoholics. Addict Behav. 1997;22:247-255.

25. Barry MJ, Edgman-Levitan S. Shared decision making - pinnacle of patient-centered care. N Engl J Med. 2012;366:780-781.

26. Cochrane Collaboration. 2011. Cochrane Handbook for Systematic Reviews of Interventions Version 5.1.0.2011.

27. McMillan SS, Kendall E, Sav A, et al. Patient-centered approaches to health care: a systematic review of randomized controlled trials. Med Care Res Rev. 2013;70:567-596.

28. Mdege ND, Fayter D, Watson JM, Stirk L, Sowden A, Godfrey C. Interventions for reducing alcohol consumption among general hospital inpatient heavy alcohol users: a systematic review. Drug Alcohol Depend. 2013;131:1-22.

29. Bazargan-Hejazi S, Bing E, Bazargan M, et al. Evaluation of a brief intervention in an inner-city emergency department. Ann Emerg Med. 2005;46:67-76.

30. Bischof G, Grothues JM, Reinhardt S, Meyer C, John U, Rumpf HJ. Evaluation of a telephone-based stepped care intervention for alcoholrelated disorders: a randomized controlled trial. Drug Alcohol Depend. 2008;93:244-251.

31. Brown TG, Dongier M, Ouimet MC, et al. Brief motivational interviewing for DWI recidivists who abuse alcohol and are not participating in DWI intervention: a randomized controlled trial. Alcohol Clin Exp Res. 2010;34:292-301.

32. Carey KB, Carey MP, Maisto SA, Henson JM. Brief motivational interventions for heavy college drinkers: a randomized controlled trial. J Consult Clin Psychol. 2006;74:943-954.

33. Chang G, Fisher ND, Hornstein MD, et al. Brief intervention for women with risky drinking and medical diagnoses: a randomized controlled trial. J Subst Abuse Treat. 2011;41:105-114.

34. Cherpitel CJ, Korcha RA, Moskalewicz J, Swiatkiewicz G, Ye Y, Bond J. Screening, brief intervention, and referral to treatment (SBIRT): 12-month outcomes of a randomized controlled clinical trial in a Polish emergency department. Alcohol Clin Exp Res. 2010;34:1922-1928.

35. Daeppen J-B, Gaume J, Bady P, et al. Brief alcohol intervention and alcohol assessment do not influence alcohol use in injured patients treated in the emergency department: a randomized controlled clinical trial. Addiction. 2007;102:1224-1233.

36. Daeppen JB, Bertholet N, Gaume J, Fortini C, Faouzi M, Gmel G. Efficacy of brief motivational intervention in reducing binge drinking in young men: a randomized controlled trial. Drug Alcohol Depend. 2011; 113:69-75.

37. D’Onofrio G, Pantalon MV, Degutis LC, et al. Brief intervention for hazardous and harmful drinkers in the emergency department. Ann Emerg Med. 2008;51:742-750.e742.

38. Emmen MJ, Schippers GM, Wollersheim H, Bleijenberg G. Adding psychologist's intervention to physicians' advice to problem drinkers in the outpatient clinic. Alcohol Alcohol. 2005;40:219-226.

39. Gaume J, Gmel G, Faouzi M, Bertholet N, Daeppen J-B. Is brief motivational intervention effective in reducing alcohol use among young men voluntarily receiving it? A randomized controlled trial. Alcohol Clin Exp Res. 2011;35:1822-1830.

40. Hansen AB, Becker U, Nielsen AS, Gronbaek M, Tolstrup JS. Brief alcohol intervention by newly trained workers versus leaflets: comparison of effect in older heavy drinkers identified in a population health examination survey: a randomized controlled trial. Alcohol Alcohol. 2012;47:25-32. 
41. Lee CS, López SR, Hernández L, et al. A cultural adaptation of motivational interviewing to address heavy drinking among Hispanics. Cultur Divers Ethnic Minor Psychol. 2011;17(3):317-324.

42. Murphy JG, Duchnick JJ, Vuchinich RE, et al. Relative efficacy of a brief motivational intervention for college student drinkers. Psychol Addict Behav. 2001;15:373-379.

43. Murphy JG, Benson TA, Vuchinich RE, et al. A comparison of personalized feedback for college student drinkers delivered with and without a motivational interview. J Stud Alcohol. 2004;65:200-203.

44. Senft RA, Polen MR, Freeborn DK, Hollis JF. Brief intervention in a primary care setting for hazardous drinkers. Am J Prev Med. 1997;13:464 470

45. Soderstrom CA, DiClemente CC, Dischinger PC, et al. A controlled trial of brief intervention versus brief advice for at-risk drinking trauma center patients. J Trauma. 2007;62:1102.

46. Aalto M, Saksanen R, Laine P, et al. Brief intervention for female heavy drinkers in routine general practice: a 3-year randomized, controlled study. Alcohol Clin Exp Res. 2000;24:1680-1686.

47. Aalto M, Seppa K, Mattila P, et al. Brief intervention for male heavy drinkers in routine general practice: a three-year randomized controlled study. Alcohol Alcohol. 2001;36:224-230.

48. Allen E, Polikina O, Saburova L, et al. The efficacy of a brief intervention in reducing hazardous drinking in working age men in Russia: the HIM (Health for Izhevsk men) individually randomised parallel group exploratory trial. Trials. 2011;12:238.

49. Beich A, Gannik D, Saelan H, Thorsen T. Screening and brief intervention targeting risky drinkers in Danish general practice - a pragmatic controlled trial. Alcohol Alcohol. 2007;42:593-603.

50. Brown RL, Saunders LA, Bobula JA, Mundt MP, Koch PE. Randomized-controlled trial of a telephone and mail intervention for alcohol use disorders: three-month drinking outcomes. Alcohol Clin Exp Res. 2007;31:1372-1379.

51. Curry SJ, Ludman EJ, Grothaus LC, Donovan D, Kim E. A randomized trial of a brief primary-care-based intervention for reducing at-risk drinking practices. Health Psychol. 2003;22:156-165.

52. D'Onofrio G, Fiellin DA, Pantalon MV, et al. A brief intervention reduces hazardous and harmful drinking in emergency department patients. Ann Emerg Med. 2012;60:181-192.

53. Hermansson U, Helander A, Brandt L, Huss A, Rönnberg S. Screening and brief intervention for risky alcohol consumption in the workplace: results of a 1-year randomized controlled study. Alcohol Alcohol. 2010;45:252-257.

54. Longabaugh R, Woolard RE, Nirenberg TD, et al. Evaluating the effects of a brief motivational intervention for injured drinkers in the emergency department. J Stud Alcohol. 2001;62:806-816.

55. Maisto SA, Conigliaro J, McNeil M, Kraemer K, Conigliaro RL, Kelley ME. Effects of two types of brief intervention and readiness to change on alcohol use in hazardous drinkers. J Stud Alcohol. 2001;62:605-614.

56. Mello MJ, Baird J, Nirenberg TD, Lee C, Woolard R, Longabaugh R. DIAL: a randomised trial of a telephone brief intervention for alcohol. Inj Prev. 2013;19:44-48.

57. Monti PM, Barnett NP, Colby SM, et al. Motivational interviewing versus feedback only in emergency care for young adult problem drinking. Addiction. 2007;102:1234-1243.

58. Noknoy S, Rangsin R, Saengcharnchai P, Tantibhaedhyangkul U, McCambridge J. RCT of effectiveness of motivational enhancement therapy delivered by nurses for hazardous drinkers in primary care units in Thailand. Alcohol Alcohol. 2010;45:263-270.
59. Sellman JD, Sullivan PF, Dore GM, Adamson SJ, MacEwan I. A randomized controlled trial of motivational enhancement therapy (MET) for mild to moderate alcohol dependence. J Stud Alcohol. 2001; 62:389-396

60. Sommers MS, Lyons MS, Fargo JD, et al. Emergency department-based brief intervention to reduce risky driving and hazardous/harmful drinking in young adults: a randomized controlled trial. Alcohol Clin Exp Res. 2013;37:1753-1762.

61. Project MATCH secondary a priori hypotheses. Project MATCH Research Group. Addiction. 1997;92:1671-1698.

62. Team UR. Effectiveness of treatment for alcohol problems: findings of the randomised UK alcohol treatment trial (UKATT). BMJ. 2005;331:541.

63. Shakeshaft AP, Bowman JA, Burrows S, Doran CM, Sanson-Fisher RW Community-based alcohol counselling: a randomized clinical trial. Addiction. 2002;97:1449-1463.

64. Mann K, Bladstrom A, Torup L, Gual A, van den Brink W. Extending the treatment options in alcohol dependence: a randomized controlled study of as-needed nalmefene. Biol Psychiatry. 2013;73:706-713.

65. Gual A, He Y, Torup L, van den Brink W, Mann K, for the ESG. A randomised, double-blind, placebo-controlled, efficacy study of nalmefene, as-needed use, in patients with alcohol dependence. Eur Neuropsychopharmacol. 2013;23:1432-1423.

66. Karhuvaara S, Simojoki K, Virta A, et al. Targeted nalmefene with simple medical management in the treatment of heavy drinkers: a randomized double-blind placebo-controlled multicenter study. Alcohol Clin Exp Res. 2007;31:1179-1187.

67. Heinala P, Alho H, Kiianmaa K, Lonnqvist J, Kuoppasalmi K, Sinclair JD. Targeted use of naltrexone without prior detoxification in the treatment of alcohol dependence: a factorial double-blind, placebocontrolled trial. J Clin Psychopharmacol. 2001;21:287-292.

68. Kranzler HR, Tennen H, Armeli S, et al. Targeted naltrexone for problem drinkers. J Clin Psychopharmacol. 2009;29:350-357.

69. Rollnick S, Miller WR. What is motivational interviewing? Behav Cogn Psycoth. 1995;23:325-334.

70. Sinclair J, Chick J, Sorensen P, Kiefer F, Batel P, Gual A. Can alcohol dependent patients adhere to an 'as-needed' medication regimen? Eur Addict Res. 2014;20:209-217.

71. Foxcroft DR, Coombes L, Wood S, Allen D, Almeida Santimano NM. Motivational interviewing for alcohol misuse in young adults. Cochrane Database Syst Rev. 2014;8:CD007025.

72. World Health Organization. Alcohol in the European Union: Consumption, Harm and Policy Approaches 2012. 2012. Available from: http:// www.euro.who.int/_data/assets/pdf_file/0003/160680/e96457.pdf. Accessed December 1, 2015.

73. Kohn R, Saxena S, Levav I, Saraceno B. The treatment gap in mental health care. Bull World Health Organ. 2004;82:858-866.

74. McQueen J, Howe TE, Allan L, Mains D, Hardy V. Brief interventions for heavy alcohol users admitted to general hospital wards. Cochrane Database Syst Rev. 2011;CD005191.

75. van den Brink W, Sorensen P, Torup L, Mann K, Gual A, for the SSG Long-term efficacy, tolerability and safety of nalmefene as-needed in patients with alcohol dependence: a 1-year, randomised controlled study. J Psychopharmacol. 2014;28:733-744.

\section{Dovepress}

\section{Publish your work in this journal}

Patient Preference and Adherence is an international, peer-reviewed, open access journal that focuses on the growing importance of patient preference and adherence throughout the therapeutic continuum. Patient satisfaction, acceptability, quality of life, compliance, persistence and their role in developing new therapeutic modalities and compounds to optimize clinical outcomes for existing disease states are major areas of interest for the journal. This journal has been accepted for indexing on PubMed Central. The manuscript management system is completely online and includes a very quick and fair peer-review system, which is all easy to use. Visit http://www. dovepress.com/testimonials.php to read real quotes from published authors. 